Rok XVI (2021) | 1 (31) | S. 263-269

https://doi.org/10.12797/LV.16.2021.31.21

Licencja: CC BY-NC-ND 4.0

Mirosława Mycawka ๑

Uniwersytet Jagielloński, Kraków

miroslawa.mycawka@uj.edu.pl

\title{
ZAGADNIENIA POPRAWNOŚCI JĘZYKOWEJ W PRACACH WITOLDA TASZYCKIEGO
}

\begin{abstract}
Słowa klucze: Witold Taszycki, kultura języka, poprawność językowa
Keywords: Witold Taszycki, culture of language, language correctness
\end{abstract}

Poprawność językowa i kultura języka nie należały do głównego nurtu zainteresowań językoznawczych Witolda Taszyckiego, w przeciwieństwie do historii języka polskiego i onomastyki, które były filarami działalności naukowej tego wybitnego badacza. Trzeba jednak przyznać, że zajmując się staropolską antroponimią, nazwami miejscowymi, polszczyzną najdawniejszych zabytków języka polskiego i wieloma innymi jeszcze zagadnieniami, mimowolnie przyczyniał się do kształtowania świadomości językowej czytelników, co można uznać za działalność odnoszącą się do kultury języka. Jest kilka tropów życiorysu naukowego W. Taszyckiego, w których na pierwszy plan wybijają się problemy poprawnościowe. Najbardziej znana jest jego wieloletnia aktywność dotycząca ortografii. Była ona wynikiem powołania go w skład Komitetu Ortograficznego PAU w 1935 r. Będąc członkiem komisji interpunkcyjnej, we współpracy ze Stanisławem Jodłowskim opracował i opublikował w 1936 r. we Lwowie Zasady pisowni polskiej i interpunkcji ze słownikiem ortograficznym (Jodłowski, Taszycki 1936b) oraz Słowniczek ortograficzny z zasadami pisowni dla uczniów szkół powszechnych (Jodłowski, Taszycki 1936a). Wspólnie z S. Jodłowskim opracował także w 1939 r. Słownik ortograficzny i prawidła pisowni polskiej, wydany w 1946 r. (Jodłowski, Taszycki 1946). Publikacje te były wielokrotnie wznawiane, stając się źródłem wiedzy ortograficzno-interpunkcyjnej wielu pokoleń Polaków. 
Czasami Taszycki odnosił się szczegółowo do zasad pisowni. Uważał m.in. za błędny sposób zapisywania z łącznikiem dwuczęściowych nazw miejscowych z członami rzeczownikowymi, które nie są równorzędne. W nazwie Kraków Płaszów drugi człon oznacza część pierwszego, zatem Kraków jest członem nadrzędnym, Płaszów zaś podrzędnym. W związku z tym nazwa powinna być pisana bez łącznika, podobnie jak: Busko Zdrój, Kraków Bonarka, Warszawa Praga i in. Inaczej rzecz ma się z nazwami, których człony są równorzędne, gdyż są nazwami osobnych miejscowości. Powinien w nich między składnikami występować w zapisie łącznik jako ekwiwalent spójnika $i$, np. Bielsko-Biała (bo to Bielsko i Biała) (por. Taszycki 1974, 1976).

Inny szczegółowy problem ortograficzny, którego rozwiązaniem zajął się Taszycki, to pisownia nazwy górniczego święta obchodzonego w dniu św. Barbary. Otóż według uczonego możliwy jest tylko zapis Barbórka, zgodny z wymową w śląskich gwarach, polegającą na realizacji dźwięku pośredniego pomiędzy o oraz $u$ (nie zaś $u$ ). Sama nazwa wywodzi się natomiast od żeńskiego imienia Barbara i jego zdrobnienia Barbarka, które w gwarach śląskich mają postać Barbora, Barborka. Przed II wojną światową wspomniane święto nosiło ogólnopolską nazwę Barbarka, po wojnie natomiast przyjęło „ludową postać śląską”. W sobie właściwym, barwnym stylu wyraża Taszycki zniecierpliwienie: „Upierający się przy zdecydowanie mylnej pisowni Barburka (a są tacy!) robią wrażenie, że powtórzę za pewnym językoznawcą jego niezbyt fortunne porównanie, ludzi zgrywających się na Rejtanów w sprawach, które zaprawdę nie są tego warte" (Taszycki 1972, przedruk 1973: 75).

Bardzo ważnym polem aktywności W. Taszyckiego była działalność w Komisji Ustalania Nazw Miejscowości, powołanej do życia 1 marca 1946 r. przy Ministerstwie Administracji Publicznej. Był jej członkiem od chwili powstania, a później jej przewodniczącym. Zadaniem Komisji było przywracanie polskich nazw miejscowych na Ziemiach Odzyskanych. Było to bardzo trudne przedsięwzięcie: „Nie należały do rzadkości wypadki, że ta sama miejscowość dwie, trzy, a niekiedy cztery nazwy nosiła: inaczej nazywali ją jej nowi mieszkańcy, inaczej kolej, inaczej poczta, a jeszcze inaczej sąd czy władze, szeroko mówiąc porządkowe" (Taszycki 1968a, przedruk 1973: 10). Ważne było przy tym, aby „nazewnictwo geograficzne Ziem Odzyskanych jednolitą tworzyło całość, aby w typie nazwy nowe nie różniły się od starych. Rzecz się powiodła. W sumie nazewnictwo to najściślej polski przybrało wygląd, w tym samym stopniu, co nazewnictwo Małopolski, Wielkopolski, Mazowsza i innych polskich dzielnic, które nigdy wynarodowieniu nie uległy” (ibid.). Dzięki doskonałej znajomości mechanizmów nazwotwórczych, etymologii i gramatyki nazw, która właściwa była Taszyckiemu, a także dzięki współpracy z przedstawicielami różnych dyscyplin, wyniki prac były bardzo dobre, z czego zdawał sprawę następująco: „Z wielkim zadowoleniem przychodzi mi stwierdzić, że nie znam wypadku odgórnego uchylenia uchwały przez Komisję podjętej” (ibid.: 9). W 1948 r. w obręb prac Komisji włączono także nazwy gór, dolin, zbiorników i cieków wodnych itp., 
zmodyfikowano też w związku z tym nazwę, była to odtąd Komisja Ustalania Nazw Miejscowości i Obiektów Fizjograficznych. Dalsza działalność Komisji objęła swym zakresem województwa centralne, południowe i wschodnie. Prowadzono badania terenowe, a zgromadzony materiał publikowano $\mathrm{w}$ postaci osobnych książeczek. Pierwsza z nich, zatytułowana Urzędowe nazwy miejscowości i obiektów fizjograficznych, z 1963 r. (Taszycki 1963) zawierała nazewnictwo Krakowa i powiatu krakowskiego. Nie umieszczono w niej natomiast nazw ulic i placów. Pieczę nad nimi sprawowały odpowiednie instancje administracji miejskiej (rady narodowe). Niestety, czyniły to niezbyt sumiennie. Zdarzały się tabliczki zawierające błędne zapisy nazw ulic. Taszycki osobiście interweniował w sprawie skorygowania błędu w nazwie ulicy w pobliżu Uniwersytetu Jagiellońskiego, jak się okazało, bezskutecznie. Owocem prac nad repolonizacją nazw na Ziemiach Odzyskanych był szereg opracowań poszczególnych zbiorów nazw, m.in. Nazwa rzeczna i miejscowa Nysa (1945), W obronie śląskich nazw miejscowych (1946), Nazwy wrocławskich dzielnic i przedmieści (1948), Sudeckie nazwy górskie (1949b). W ustalaniu nazw pasma sudeckiego niezwykle ważna była rola arbitra - specjalisty z zakresu onomastyki - w osobie Taszyckiego. Wstępną wersję spisu nazw opracowało bowiem Polskie Towarzystwo Tatrzańskie, niemające w swym składzie językoznawcy. Zaowocowało to włączeniem do oronimów „nic nie znaczących dziwolągów w rodzaju Hubryk, Jeślak, Turkacz, Uprzyk, Żyrlik” oraz „niby coś wyrażających, ale źle pod względem słowotwórczym ukutych formacji, jak Bardziel, Lisier, Molkówka, Nienasytec, Widałek", a także niezasadnych w odniesieniu do tych terenów nazw proweniencji wołoskiej „Grapa, Kiczera, Młaka” (ibid., przedruk 1968: 210). Interwencja Taszyckiego zapobiegła, jak widać, wdrożeniu nazw bardziej czasem przypominających neologizmy Bolesława Leśmiana niż zgodne ze zwyczajami językowymi nazewnictwo górskie. Na temat nazw, także w aspekcie poprawnego ustalania ich etymologii, uczony wypowiadał się bardzo wiele razy. Przykładem może być artykuł, w którym odnosił się do niewłaściwie ustalonego pochodzenia nazw typu Konary, Kuchary, Piekary, które Henryk Gaertner (1934: 286) niesłusznie wywodził od wyrazów zakończonych na -ar (ciężar, dźwigar). Taszycki (1934) dowiódł, że są to nazwy służebne, oznaczające pierwotnie mieszkańców (konarzy, kucharzy, piekarzy), będących niegdyś wykonawcami służebności na rzecz dworów czy klasztorów, występujące w formach pierwotnego biernika.

Bardziej praktyczny, użytkowy charakter mają artykuły odwodzące od stosowania błędnych form i wskazujące, jakie formy w ich miejsce powinny być używane. W tekście z 1953 r. wytyka Taszycki krakowskim dziennikarzom niewłaściwe stosowanie wyrazów nowohutniczanie (nowohutniczanin, nowohutniczanka) nazywających mieszkańców Nowej Huty i wyderywowanego z tej nazwy przymiotnika nowohutnicki. Słusznie argumentuje, że takie formy byłyby zasadne, gdyby miejscowość nosiła nazwę Nowe Hutniki. Zaleca stosowanie form nowohucianie (nowohucianin, nowohucianka), nowohucki (Taszycki 1953c). Z dzisiejszej perspektywy można ocenić, że zalecenia zostały wykonane, formy prawidłowe się przyjęły. 
Za przejaw językowego niechlujstwa uznawał Taszycki przedstawianie siebie lub kogoś poprzez używanie imienia i nazwiska w odwróconej kolejności - najpierw wymieniając nazwisko, potem imię. Usprawiedliwiał taki porządek jedynie w alfabetycznych spisach stosowanych w indeksach osobowych, urzędowych wykazach itp. W innych okolicznościach zdecydowanie zalecał układ imię - nazwisko. Tłumaczył to istotą obu członów: imię jako człon wyróżniający powinno być na pierwszym miejscu, nazwisko zaś jako element utożsamiający - na drugim. Uważał, że naruszanie tego uświęconego wielowiekową tradycją porządku „niezbyt dobrze świadczy o kulturze językowej przeciwników dawnego w tym zakresie zwyczaju” (Taszycki 1949a; przedruk 1958: 166).

Krytycznie się odniósł Taszycki do zaproponowanej przez autorów pewnego zbioru nazw geograficznych świata formy India zamiast Indie. Z charakterystycznym sarkazmem napisał, odnosząc się do pozytywnej rekomendacji książki stosującej formę India przez Prezydium i Komisję Kultury Języka Komitetu Językoznawstwa PAN (mimo licznych błędów), że „Posługiwanie się nią nie jest obowiązkiem. Jak ktoś gwałtownie chce, może to robić dowolnie. Konstytucja tego nie zabrania" (Taszycki 1968b, przedruk 1973: 130). Jeszcze żywiej zareagował na propozycję autorów tejże nieszczęsnej publikacji, by Ocean Indyjski nazywać Indykiem: „To świetny pomysł. Jak niesłychanie upraszcza on terminologię geograficzną. "Osiągnięcie« to naukowe wysokiej klasy" (ibid.: 131).

Z kolei w artykule z 1969 r. przestrzegał Taszycki przed używaniem rusycyzmu unikalny 'stanowiący unikat, jedyny w swoim rodzaju, wyjątkowy', który pojawił się w polszczyźnie po II wojnie światowej. Zarzucał stosującym go dziennikarzom brak dbałości o czystość języka polskiego, wskazując przy okazji języki rosyjski i angielski jako te, z których strony czyha niebezpieczeństwo wpływania na język polski i tym samym zaśmiecania polszczyzny obcymi wyrazami (Taszycki 1969).

Bardzo ważnym nurtem w działalności naukowej W. Taszyckiego były badania nad kształtowaniem się polszczyzny literackiej i normy językowej, a także odtworzeniem przebiegu zmagań polszczyzny z żywiołami obcych języków w procesie wykształcania się jej statusu jako języka w pełni funkcjonalnego. Efektem tych badań jest przede wszystkim książka Obrońcy języka polskiego. Wiek XV-XVIII wydana w 1953 r. w Bibliotece Narodowej (Taszycki 1953b). Ten obszerny wybór tekstów daje świadectwo podejmowania, czasem karkołomnych, prób posługiwania się językiem ojczystym wbrew obowiązującym zwyczajom oraz czynienia wysiłków służących rozwojowi polszczyzny i jej obronie przed dominacją innych języków w przestrzeni publicznej. We wstępie autor antologii przedstawia burzliwe dzieje torowania i blokowania językowi polskiemu drogi prowadzącej do obecności w literaturze, sądach, urzędach, szkolnictwie, kościele. Pokazuje, jakim trudnym zadaniem była uprawa języka ojczystego, pokonanie niechęci do niego wobec bardzo mocnej pozycji łaciny i silnych wpływów innych języków (czeskiego, później francuskiego), a w końcu stawianie na rozwój polszczyzny, kiedy łatwiejszym i mniej czasochłonnym zajęciem 
wydawało się wyrażanie myśli w innych, bardziej literacko i w ogóle funkcjonalnie wykształconych językach. Każde stulecie dodawało do listy obrońców języka, jak nazwał Taszycki wszystkich orędowników rozwijania polszczyzny i posługiwania się nią, kolejne nazwiska ludzi wykształconych, wysoko postawionych w hierarchii społecznej, ludzi możnych, niektórych władców, pisarzy, reformatorów ortografii, drukarzy. Ci ostatni szczególne położyli zasługi dla znormatywizowania zasad polskiej pisowni, choć wielu $\mathrm{z}$ nich miało niemieckie korzenie. Tchnęli wiarę $\mathrm{w}$ to, że - jak wyznał Hieronim Wietor - naród polski swój język „mógłby iście [...] obfitością i krasomową z każdem innem porównać” (ibid.: XXI). „Na szczęście - jak pisze Taszycki - rzucone wówczas przez Unglera wezwanie: »Jedno wy, mili Polacy, [...] rozmiłujcie się języka swego" (posłowie do książki S. Falimirza O ziołach i mocy jich, 1534) nie przebrzmiało bez echa" (ibid.: XXIII). XVI wiek za sprawą wielu uzdolnionych pisarzy z najwybitniejszym - Janem Kochanowskim - na czele okazał się stuleciem narodzin polskiego języka literackiego, narażonego później co prawda wielokrotnie na niekorzystne wpływy innych języków, jednak wychodzącego z tych opresji zwycięsko i stale (poza przejściowym regresem w XVII i aż do połowy XVIII w.) rozwijającego się. Książka Obrońcy języka polskiego, a także artykuły Uprawa języka polskiego w dobie Odrodzenia (Taszycki 1961) i Kultura języka polskiego Renesansu (Taszycki 1953a) pokazują meandry kształtowania się zasad poprawności językowej i wieloodmianowej funkcjonalności polszczyzny, ucząc jednocześnie szacunku dla potężnego wysiłku wielu pokoleń użytkowników i miłośników języka polskiego.

Podsumowując, z konieczności skrótowy, przegląd prac W. Taszyckiego dotyczących poprawności i kultury języka polskiego, trzeba podkreślić, że ogromny dorobek historycznojęzykowy i onomastyczny tego uczonego stanowi fundament wyznaczania norm w odniesieniu do wielu fenomenów języka i bez jego wkładu naukowego do polskiego językoznawstwa wiele dylematów, także poprawnościowych, pozostałoby nierozstrzygniętych.

\section{Literatura}

Gaertner H., 1934, Gramatyka współczesnego jezzyka polskiego, cz. III: Słowotwórstwo, Lwów.

JodŁOWSKi S., TASZYCKI W., 1936a, Stowniczek ortograficzny z zasadami pisowni dla uczniów szkół powszechnych, Lwów.

JoDŁOWSKi S., TASZYCKI W., 1936b, Zasady pisowni polskiej i interpunkcji ze stownikiem ortograficznym, Lwów.

JodŁOWSKI S., TASZYCKi W., 1946, Słownik ortograficzny i prawidła pisowni polskiej, Toruń. TAszYcKi W., 1934, W sprawie pochodzenia nazw miejscowych typu Konary, Kuchary, Piekary itp. (Z powodu Gramatyki współczesnego języka polskiego H. Gaertnera), „Slavia Occidentalis" 13, s. 121-126; przedruk w: idem, Rozprawy i studia polonistyczne, t. I: Onomastyka, Wrocław - Kraków 1958, s. 174-177. 
Taszycki W., 1945, Nazwa rzeczna i miejscowa Nysa, „Język Polski” XXV, s. 7-11; przedruk w: idem, Rozprawy i studia polonistyczne, t. I: Onomastyka, Wrocław 1958, s. 321-324.

TAszYCKI W., 1946, W obronie śląskich nazw miejscowych, „Zaranie Śląskie” XVII, s. 52-55; przedruk w: idem, Rozprawy i studia polonistyczne, t. I: Onomastyka, Wrocław 1958, s. 325-331.

TAszycKi W., 1948, Nazwy wrocławskich dzielnic i przedmieści, „Komunikat Instytutu Śląskiego", seria VII, nr 13, Katowice; przedruk w: idem, Rozprawy i studia polonistyczne, t. I: Onomastyka, Wrocław 1958, s. 334-338.

Taszycki W., 1949a, Najpierw imię, potem nazwisko, „Poradnik Językowy” nr 3, s. 22-23; przedruk w: idem, Rozprawy i studia polonistyczne, t. I: Onomastyka, Wrocław 1958, s. $165-166$.

TAszYcki W., 1949b, Sudeckie nazwy górskie, „Przegląd Zachodni” nr 7-8, s. 110-112; przedruk w: idem, Rozprawy i studia polonistyczne, t. IV: Onomastyka i historia jezzyka polskiego, Wrocław 1968, s. 209-211.

TAszyCKi W., 1953a, Kultura języka polskiego Renesansu, „Materiały dyskusyjne Sesji Naukowej Odrodzenia" PAN, Warszawa (maszynopis powielany).

TAszycki W., 1953b, Obrońcy języka polskiego. Wiek XV-XVIII, Wrocław.

TAszYCKI W., 1953C, Wyrazy pochodne od nazwy miejscowej Nowa Huta, „Poradnik Językowy" nr 2, s. 25-26; przedruk w: idem, Rozprawy i studia polonistyczne, t. I: Onomastyka, Wrocław 1958, s. 339-340.

TAszycki W., 1961, Uprawa języka polskiego w dobie Odrodzenia, „Zeszyty Naukowe Uniwersytetu Jagiellońskiego”, „Prace Językoznawcze”, nr 37, s. 7-26; przedruk w: idem, Rozprawy i studia polonistyczne, t. III: Historia języka polskiego, Wrocław 1965, s. 262-281.

TAszycKi W. (red. nauk. całości), 1963, Urzędowe nazwy miejscowości i obiektów fizjograficznych, cz. 1: Miasto Kraków i powiat krakowski, red. M. Karaś, A. Zaręba, Warszawa.

TAszycki W., 1968a, Zadania i osiagnięcia Komisji Ustalania Nazw Miejscowości i Obiektów Fizjograficznych przy Prezesie Rady Ministrów, „Gospodarka i Administracja Terenowa” nr 4, s. 11-12; przedruk w: idem, Rozprawy i studia polonistyczne, t. V: Onomastyka i historia języka polskiego, Wrocław 1973, s. 9-13.

TAszYcki W., 1968b, O Indiach i śmiesznym Indyku, „Życie Literackie” XVIII, nr 7, s. 15; przedruk w: idem, Rozprawy i studia polonistyczne, t. V: Onomastyka i historia języka polskiego, Wrocław 1973, s. 130-131.

TAszycki W., 1969, Przymiotnik unikalny, „Język Polski” XLIX, s. 68-70; przedruk w: idem, Rozprawy i studia polonistyczne, t. V: Onomastyka i historia języka polskiego, Wrocław 1973, s. 207-209.

TASZYCKI W., 1972, Imię żeńskie Barbora 'Barbara' oraz jego zdrobnienia Barborka $i$ Barbórka, „Język Polski” LII, s. 261-265; przedruk w: idem, Rozprawy i studia polonistyczne, t. V: Onomastyka i historia języka polskiego, Wrocław 1973, s. 72-75.

TAszycki W., 1974, Pisownia nazw miejscowych złożonych $z$ dwu członów rzeczownikowych, „Poradnik Językowy” nr 7, s. 356-357.

TASZYCKI W., 1976, Wyjaśnienia na temat pisowni nazw miejscowych złożonych $z$ dwu członów rzeczownikowych, „Język Polski” LVI, s. 218-219. 


\section{Language Correctness in the Writings of Witold Taszycki Summary}

The author of the article presents a brief description of the activities of Witold Taszycki related to language correctness and the culture of Polish language. These activities are included in the scholar's several fields of work, such as: a) working on establishing and describing the principles of Polish spelling and punctuation, as well as some detailed aspects of these areas; b) participating in the Commission for Creating the Names of Places, and then directing the commission's works; c) analysis of shaping the Polish literary language and language standard, as well as reconstructing the process of struggling of Polish with the influence of foreign languages in the course of separating the status of Polish as a language that is entirely functional. The results of such activities include spelling dictionaries which contain the descriptions of the principles of punctuation and spelling, statements related to names of places and areas, books on the culture of the Old Polish language, as well as many other texts. They constitute a lasting contribution of Witold Taszycki into shaping the culture of the word and the language identity of Polish people. 